\title{
The internal layering of Pine Island Glacier, West Antarctica, from airborne radar-sounding data
}

\author{
Nanna B. KARLSSON, ${ }^{1,2}$ David M. RIPPIN, ${ }^{1}$ David G. VAUGHAN, ${ }^{2}$ Hugh F.J. CORR ${ }^{2}$ \\ ${ }^{1}$ Department of Geography, University of Hull, Hull HU6 7RX, UK \\ E-mail:n.b.karlsson@2006.hull.ac.uk \\ ${ }^{2}$ British Antarctic Survey, Natural Environment Research Council, Madingley Road, Cambridge CB3 OET, UK
}

\begin{abstract}
This paper presents an overview of internal layering across Pine Island Glacier, West Antarctica, as measured from airborne-radar data acquired during a survey conducted by the British Antarctic Survey and the University of Texas in the 2004/05 season. Internal layering is classified according to type (continuous/discontinuous/missing) and the results compared with InSAR velocities. Several areas exhibit disruption of internal layers that is most likely caused by large basal shear stresses. Signs of changes in flow were identified in a few inter-tributary areas, but overall the layering classification and distribution of layers indicate that only minor changes in ice-flow regime have taken place. This is supported by bed-topography data that show the main trunk of the glacier, as well as some of the tributaries, are topographically controlled and located in deep basins.
\end{abstract}

\section{INTRODUCTION}

Pine Island Glacier (PIG) is one of the fastest-flowing and most rapidly changing ice-drainage catchments in West Antarctica. The catchment covers an area of $\sim 175000 \mathrm{~km}^{2}$ of the West Antarctic ice sheet (WAIS) and comprises two main basins: a southern, more-inland and slower-flowing basin and a northern, faster-flowing basin feeding into the Amundsen Sea embayment via Pine Island Ice Shelf (Fig. 1; Vaughan and others, 2006). Observations from satellite radar interferometry have shown a retreat of the grounding line of $\sim 1 \mathrm{~km} \mathrm{a}^{-1}$ (Wingham and others, 2006) and a decrease in ice thickness of $3.5 \pm 0.9 \mathrm{mice}^{-1}$ during the period 1992-96 (Rignot, 1998). Two marked episodes of acceleration across the grounding line have been observed over the last 35 years (Rignot, 2002; Joughin and others, 2003), and the flow there accelerated by $34 \%$ between 1996 and 2005 (Rignot and others, 2008). The changes in PIG are well documented, but it remains unclear whether they are a response to ongoing climate change or natural fluctuations that do not impact the long-term equilibrium of the ice sheet (Vaughan and others, 2006).

During the 2004/05 austral summer, a consortium of the British Antarctic Survey (BAS) and the University of Texas (UT) performed coordinated airborne radio-echo sounding (RES), gravimetric and magnetic surveys over the principal catchments draining into the Amundsen Sea embayment (Holt and others, 2006; Vaughan and others, 2006). Each institute used its own aircraft and instrumentation; here we focus only on the survey across PIG (described in more detail by Vaughan and others, 2006); a description of the survey that covered the Thwaites, Smith and Kohler basins, including aircraft and instrumentation details, can be found in Holt and others (2006). The data from PIG comprise $\sim 35000 \mathrm{~km}$ of airborne RES data, collected by the icesounding radar system PASIN (Polarimetric Airborne Survey INstrument) mounted on an aircraft also equipped with dual-frequency carrier-wave GPS (global positioning system) for navigation, a radar altimeter, wing-tip magnetometers and a gravity meter; only the PASIN data are analysed in this paper. PASIN collected data with a transmit power of $4 \mathrm{~kW}$ around a central frequency of $150 \mathrm{MHz}$. The system was configured such that a $0.1 \mu$ s pulse, optimized for imaging near-surface layering, was interleaved with a $4 \mu \mathrm{s}, 10 \mathrm{MHz}$ chirp, optimized for detecting the basal reflector in ice up to $4.2 \mathrm{~km}$ thick (see Corr and others, 2007, for further details of PASIN). While the principal aim of the RES survey was to image the bed and map subglacial topography across PIG (see Vaughan and others, 2006, for further details), the 'chirp' data also imaged numerous deep internal layers which form the focus of this paper.

Figure 2 shows the subglacial topography across the northern basin of PIG determined from PASIN (after Vaughan and others, 2006), over which are superimposed surface ice-flow velocities determined from InSAR (interferometric synthetic

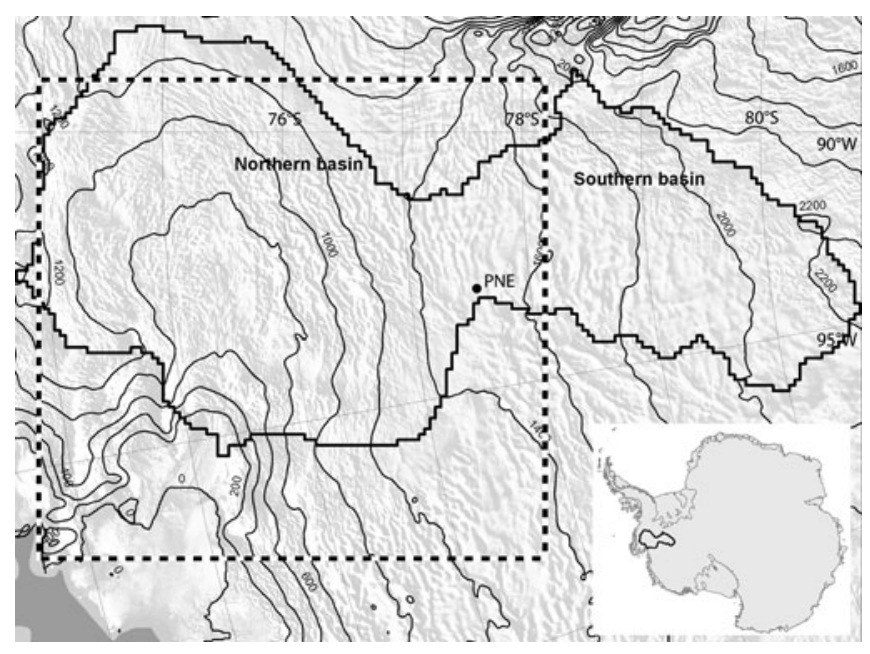

Fig. 1. The Pine Island Glacier catchment, showing its division into a northern basin and a southern basin. The base camp from which the BAS-UT surveys operated is marked PNE. Surface topographic contours at $200 \mathrm{~m}$ intervals are derived from Bamber and Gomez-Dans (2005); the background imagery is from the MODIS (moderate-resolution imaging spectroradiometer) Mosaic of Antarctica (MOA; T. Haran and others, http://nsidc.org/data/nsidc0280.html). The dashed lines mark the area covered in Figures 2 and 4. 


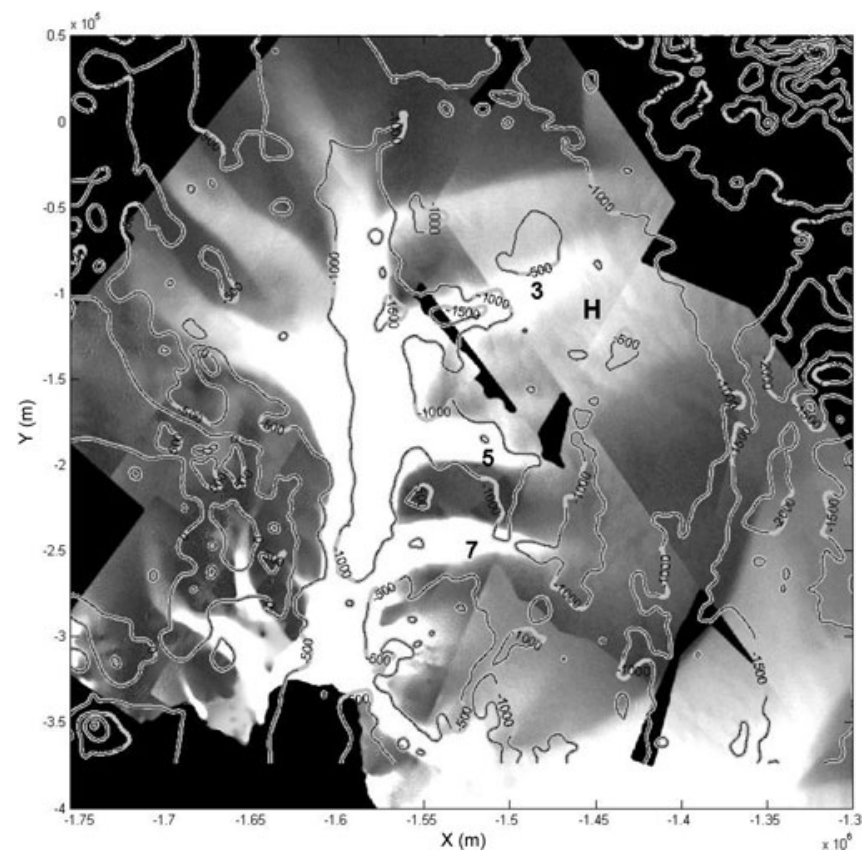

Fig. 2. Bed topography map of the northern basin of PIG $(500 \mathrm{~m}$ contours; after Vaughan and others, 2006) and surface velocities measured from InSAR by Rignot (2006). The bright areas denote fast ice flow with the main trunk of the glacier and the tributaries clearly visible. The black areas are without InSAR velocity data. The numbers 3,5 and 7 refer to the tributaries, numbered according to the scheme of Stenoien and Bentley (2000). The positions of the trunk and tributaries 3 and 5 correspond to deep, well-defined topographic channels. The bed-high separating the northern and the southern part of the glacier is seen to the right of the image, marked ' $\mathrm{H}^{\prime}$.

aperture radar) (Rignot, 2006). The map clearly shows that the main trunk of PIG is constrained by topographic channels that probably represent a preglacial geologic feature (Vaughan and others, 2006). The trunk of the glacier and two of the main tributaries (tributaries 3 and 5 in Fig. 2) lie in confined basins, while the remainder of the tributaries are not constrained by bed topography to the same extent. The bed topography shows that the northern basin of PIG, comprising the fast-flowing main trunk of the glacier and its tributaries, is separated from the slower-flowing southern basin by a bedhigh marked ' $\mathrm{H}$ ' in Figure 2. Field measurements showed that currently the bed-high does not impede ice flow from the southern to the northern basin, but due to the bed-high a possible collapse along the trunk of PIG will most likely not progress into the deepest parts of the WAIS (Vaughan and others, 2006). However, no bed topography is present to impede collapse of the northern basin in case of a retreat of the grounding line, and this collapse alone might contribute to sea-level rise by $24 \mathrm{~cm}$ (Vaughan and others, 2006).

In this paper, we focus on RES measurements of the internal layering across the northern basin of PIG, and the information they can impart about ice-flow history and past changes across the region. Numerous RES surveys from different regions of Antarctica have revealed internal layering within the ice sheets. The layers reflect changes in the dielectric properties of the ice, caused by changes in either permittivity or electrical conductivity. These changes may be due to density variations, increased impurity content or changes in ice-crystal orientation. The signal from the density variations effectively dominates in the upper part of the depth profile down to 500-1000 m depth. The variations in impurity content and ice-crystal orientation, however, occur through all depths (Fujita and others, 1999; Siegert and Fujita, 2001). Regardless of their specific origins, it is generally agreed that internal layers are isochrones and they are often traceable for $>100 \mathrm{~km}$ (e.g. Robin and Millar, 1982; Siegert, 1999; Hodgkins and others, 2000). Because the stratigraphy of internal layers is the combined result of mass balance and ice flow, internal layers can provide important information on the past behaviour of the catchment.

\section{METHODOLOGY}

We analyse internal layers from five flights flown across PIG with a constant terrain clearance of $150 \mathrm{~m}$. These flights were flown with the collection of radar data as a priority, and the radar data show numerous internal layers. Further flights undertaken primarily to acquire gravity measurements, but with PASIN still operating, were flown at constant elevation rather than constant terrain clearance. The associated radar data for these gravity flights do not contain abundant internal layers, and are therefore omitted from analysis in this paper.

Internal layers were analysed from the radar data processed as follows. The baseband radar data were sampled at $22 \mathrm{MHz}$, and coherent integration of 25 consecutive radar records was performed using hardware on the aircraft, providing an average spatial sampling interval of $0.2 \mathrm{~m}$. Postprocessing of the data commenced with chirp compression (with a Blackman window) followed by incoherent stacking of ten consecutive traces. Finally, the data were decimated to provide a complete record for every $20 \mathrm{~m}$ of alongtrack movement and converted to SEG-Y (standard format developed by the Society of Exploration Geophysicists). The surface and bed elevation were picked using the software package ProMax. Internal layers were analysed from SEG-Y profiles loaded first into the software package ReflexW.

In the classification the internal layers were divided into three different types: (1) continuous, well-defined layers; (2) discontinuous or disrupted layers; and (3) missing layers. The classification was performed manually and therefore relies on the assessment done by the person carrying out the classification. This approach to studying internal layering has already been used in several studies (e.g. Rippin and others, 2003, 2006; Siegert and others, 2003; Bingham and others, 2007) with similar classification schemes, and it has been observed that the layer type often correlates with ice-flow velocity. The studies found that continuous and well-defined layers are primarily located in areas of slow-flowing ice that have undergone little motion and few internal stresses. Disrupted layers are often coincident with fast-flowing areas or with boundaries between areas of slow and enhanced flow. This agrees well with the fact that disrupted layers are thought to be caused by high longitudinal strain in areas with fast-flowing ice or lateral shear strain at boundaries between fast- and slow-flowing ice (Jacobel and others, 1996). These boundaries can be either the margins of ice streams or of enhanced flow tributaries, even when the tributaries do not appear to have a well-defined margin (Rippin and others, 2003). In the case of missing layers, it is often not possible to distinguish between an inherent glaciological phenomenon, where the layers have been obliterated by very fast ice flow, and a reduction in echo strength due to instrument limitations. The interpretation of the missing layers with respect to surface velocity must therefore be approached with caution. 

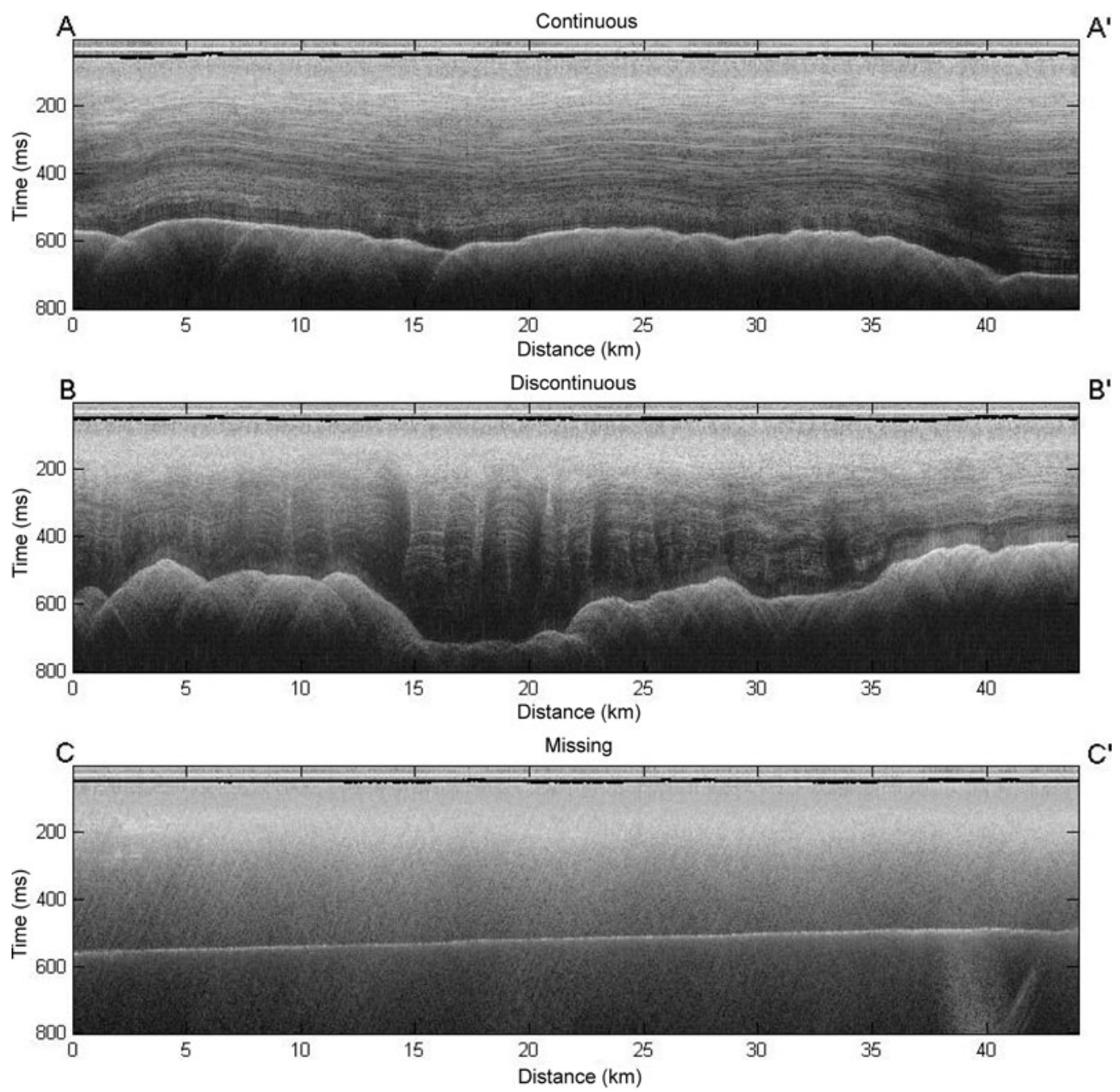

Fig. 3. Example of continuous (top), discontinuous (middle) and missing (bottom) layers. The thin black line marks the ice surface. The letters refer to the locations of the radargrams in Figure 4.

Here, the classification of internal layering into the three categories was conducted on the SEG-Y profiles directly loaded into ReflexW, as described above. The aim was to carry out the classification on data subjected to the fewest processing steps possible. After the initial classification, the background noise was removed, and the data were corrected for energy decay, so that the internal layers are picked out more clearly at depth. The layers were then reclassified, and the results used as a validation of the results from the initial classification. Examples of the different types of internal layering are shown in Figure 3. We compare our results with ice-flow velocities derived across the region from InSAR by Rignot (2006) (Fig. 2).

\section{RESULTS}

The result of the classification is shown on an InSAR surface velocity map in Figure 4. Generally, the results from the layer classification agree with findings described elsewhere (e.g. Rippin and others, 2003; Siegert and others, 2003). Areas of slow flow mainly exhibit continuous layers, while almost all of the enhanced-flow areas and their margins have either discontinuous or missing layers. The continuous layers in slow-flowing areas account for $>95 \%$ of all continuous layers. The only exception is the small area of continuous layering in tributary 3, parallel to the flow direction (Fig. 4).
The discontinuous layers are primarily, but not exclusively, found in areas with fast flow, though some discontinuity was observed in the otherwise continuous slow-moving area close to the field camp (Fig. 4). Most of the discontinuous layers can be found in tributaries, a few areas of the main trunk exhibit discontinuous layering but no layers have been identified downstream of tributary 5 (Fig. 4).

For several flight-lines, a transition in internal layering corresponds to a change in ice-surface velocity. For example, in tributary 7 the change from continuous to discontinuous layering (marked ${ }^{\prime * \prime}$ in Fig. 4) occurs at the onset of fast flow. The location of the margins in tributary 3 also correlates with a change in layer type from continuous to discontinuous. Assuming that the missing layers in the main trunk are a real physical feature, the margins of the trunk clearly correlate with a change in layer type from discontinuous to missing layers (Fig. 4).

Though the overall classification scheme does not distinguish between different kinds of discontinuous layers, the discontinuous layer class was found to cover a large range of different internal layer features. For example, quite a few areas have visible discontinuous upper layers but no visible layers in the lower part, while other areas have structures that can most easily be described as resembling 'whirlwinds' or 'tornadoes'. An example of these features is shown in Figure 3, profile $\mathrm{BB}^{\prime}$. Radargrams from these areas show 


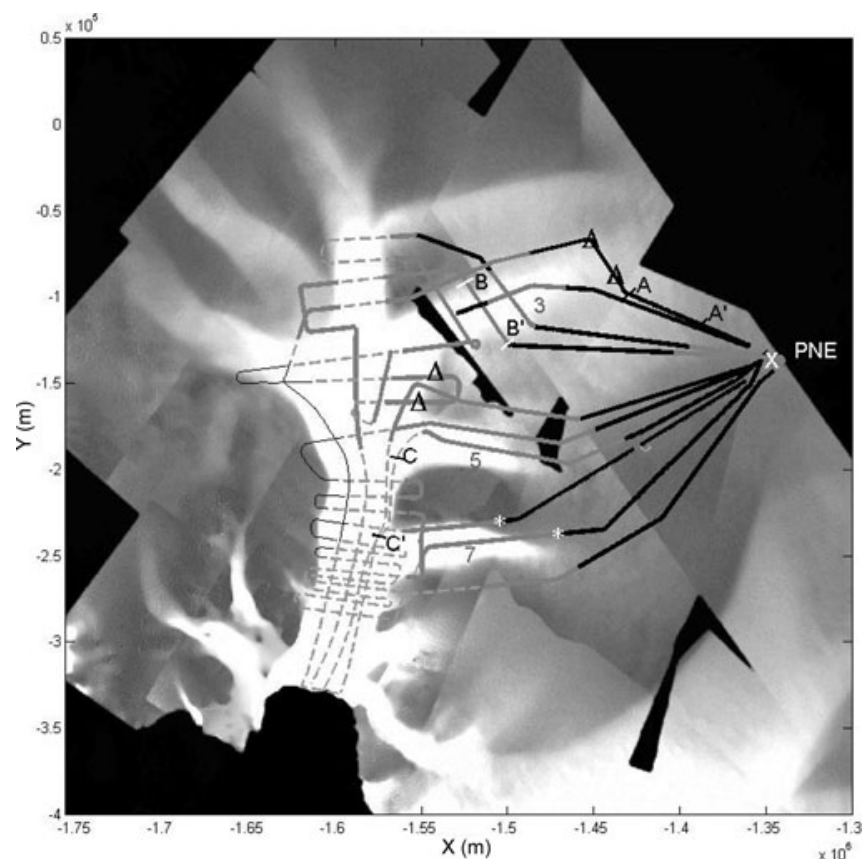

Fig. 4. Classification of internal layering along flight-lines 10-14 from the BAS-UT airborne RES survey over PIG. The thick black lines mark continuous layers, the solid grey lines discontinuous layers and dashed grey lines missing layers. Thin black lines mark profiles with one strongly reflecting layer (see Corr and Vaughan, 2008). The classification is superimposed over InSAR velocity data (Rignot, 2006). White stars denote a sudden change of layer type consistent with an onset of fast flow. Black triangles mark areas with continuous upper layers but discontinuous lower layers. As in Figure 2, numbers refer to the tributaries. The letters mark the locations of radargrams $\mathrm{AA}^{\prime}, \mathrm{BB}^{\prime}$ and $\mathrm{CC}^{\prime}$ and the PNE field camp is marked ' $\mathrm{X}$ '.

internal layers that are disrupted by vertical features penetrating almost the entire depth of the glacier. In most cases the internal layers are still visible between the vertical features, but in some areas only the vertical features themselves are visible, while the internal layers appear to have been obliterated. Whether or not these vertical features are visible appears to be strongly correlated with the incident flight direction, as they are primarily identified in flight-lines perpendicular to the flow direction, while flight-lines parallel to the flow rarely exhibit this kind of feature.

\section{DISCUSSION}

The majority of the layers classified in this study can be explained by the current flow regime of PIG. This is in good agreement with the fact that the glacier is topographically constrained and therefore unlikely to have undergone significant changes in flow configuration (Vaughan and others, 2006). Continuous layers are primarily found in the slow-flowing areas, and discontinuous layers in regions of enhanced and fast flow. Furthermore, it seems likely that the absence of layers downstream in the main trunk results from their extinction due to fast flow (cf. Jacobel and others, 1993), since none of the flights over the main trunk, including those flown for the acquisition of gravity data (not shown in Fig. 4), exhibit any layers downstream of tributary 5 .

The continuous layers identified in this study are almost exclusively located in slow-flow areas. Only one area, located in the fast-flow region of tributary 3, exhibits an 'island' of continuous layers. The continuous layering could be a sign that the disruptive processes are not active in that area. Similar 'islands' of continuous layers in fast-flow regions have been identified in a study of Wilkes Land, East Antarctica, by Rippin and others (2003), but the islands in that study were found to correlate with shallower ice thicknesses compared to the surrounding disrupted areas. The island identified in the PIG dataset, however, is located in an area with larger ice thickness than the average continuous and discontinuous area and it therefore seems unlikely that the PIG island is associated with the same processes. Previous studies have also identified 'anomalous' continuous layering within the fast-flowing Whillans Ice Stream, West Antarctica, where it was suggested that the process behind the formation was 'episodic migration' of the onset location of fast flow (Whillans and others, 1987; Bindschadler and others, 1988, 2001). The anomalous layering in tributary 3 may therefore indicate a change in the location of the tributary over the time in which the layering formed.

Discontinuous layering has been identified primarily in areas where high longitudinal stresses are expected, i.e. areas of enhanced flow or areas close to margins of tributaries or the main trunk of PIG. Again, however, there are some notable exceptions, for example in the two areas between the black triangles marked in Figure 4. These two areas display disrupted layering at depth, but more continuous layering towards the ice surface. In previous studies this type of feature has been interpreted to represent changes in flow regime, i.e. migration of fast-flow areas or changes in flow path (Rippin and others, 2003). The location of these features in PIG could be interpreted as evidence that tributary 3 once extended further south than at present and that the main trunk was either wider or its position has changed. This finding, in combination with the continuous 'island' mentioned above, suggests that the location and flow dynamics of tributary 3 are not as stable as the bed topography might suggest.

The flight-line parallel to and west of tributary 7 displays discontinuous and missing layers, even though this area is some distance from the current margin of the tributary and would therefore be expected to contain continuous layering. Assuming that the missing layers in the flightline are not a measurement artefact, the missing layers indicate that high internal stresses are, or have been, present here. Bed topography (Fig. 2) reveals that tributary 7 is not located in a particularly deep basin and it is therefore possible that the position of the tributary has changed and the main flow of the tributary was previously west of its current position. However, all the flight-lines from intertributary areas show discontinuous and/or missing layers, even between tributaries 3 and 5 that are thought to be topographically constrained. It is therefore also possible that the bed roughness, and not the surface velocity, is the main factor in disrupting the layers.

The area close to the field camp (marked ' $X$ ' on the righthand side of Fig. 4) is slow-flowing and exhibits continuous layering, apart from two of the flight-lines in which the upper layers are disrupted and layers are absent at depth. The absence of the deeper layers may be a consequence of echostrength reduction with depth, or could reflect the extinction of deeper internal layers due to high stresses. Since the area is located south of the bed-high, the bed inclines southwards while the ice flows northwards (as measured by Vaughan and others, 2006). Thus, a possible explanation for the disrupted layering, with the missing layers at depth, could be that the 
ice is subjected to large strain rates due to the slope inclining in the opposite direction to the ice flow. In other words, the ice flows 'uphill', which might lead to a build-up of strain rates large enough to disrupt the layers. That the disruption is not observed to the same extent in the other flight-lines could be due to the fact that the two flight-lines in question are the only ones parallel to the flow direction, the direction in which the disruption is taking place. To obtain a better understanding of these features, it would be necessary to include studies of bed roughness and analysis of strain rates, but that is beyond the scope of this paper and we do not discuss the formation mechanism further here.

The layer classification used here depends to some extent on the direction of the flight-line. An example of this is the vertical features, which have been identified in flight-lines perpendicular to the ice-flow direction, but not in flightlines parallel to the ice flow. The formation mechanism behind these features is unknown, but this observation indicates that their detection is coupled to the ice-flow direction. Whether they are genuine physical features that result from flow convergence and/or changes in flow mode (Leysinger Vieli and others, 2007), sticky basal conditions or simply interference patterns from the radar waves (Harrison, 1971) remains unknown.

\section{CONCLUSION}

Internal layering in airborne RES data from PIG has been classified and compared with InSAR-derived ice-surface velocities. The distribution of layer types with respect to ice-flow patterns is consistent with previous studies. More than $95 \%$ of continuous layers were found in slow-flowing areas, while areas with enhanced flow mainly exhibited discontinuous layering, as did areas close to the margins of tributaries. In the fast-flowing trunk of the glacier, internal layers were absent downstream of tributary 5 .

Since the majority of the internal layering can be explained by the current flow regime, the results from the classification indicate that no major changes have taken place in the flow regime of the glacier. This is in good agreement with the fact that the glacier is strongly topographically constrained and therefore unlikely to have undergone large changes in flow dynamics. However, disrupted internal layers upstream of the current onset of tributary 3 , and in the slow-flowing ice adjacent to tributary 3, suggest that this tributary may have been larger in the past, initiating further upstream and covering a wider area than it does now. In the same tributary, an island of continuous layering has been identified, indicating an absence of the processes causing disruption of layers in the otherwise enhanced-flow region. However, further studies incorporating analyses of the relationships of internal layering patterns with bed roughness and strain rates are required to improve our understanding of the long-term flow history of PIG interpreted from internal layering.

\section{ACKNOWLEDGEMENTS}

N.B. Karlsson was supported by a University of Hull scholarship. The authors thank all those involved in the logistical support and collection of the BAS-UT radar data over Pine Island Glacier. Reviews by M. Peters, an anonymous reviewer and the associate editor, D. Blankenship, significantly improved the manuscript. N.B. Karlsson also thanks R. Bingham for help and valuable insights.

\section{REFERENCES}

Bamber, J. and J.L. Gomez-Dans, 2005. The accuracy of digital elevation models of the Antarctic continent. Earth Planet. Sci. Lett., 237(3-4), 516-523.

Bindschadler, R.A., P.L. Vornberger, S.N. Stephenson, E.P. Roberts, S. Shabtaie and D.R. MacAyeal. 1988. Ice-shelf flow at the boundary of Crary Ice Rise, Antarctica. Ann. Glaciol., 11, 8-13.

Bindschadler, R., J. Bamber and S. Anandakrishnan. 2001. Onset of streaming flow in the Siple Coast region, West Antarctica. In Alley, R.B. and R.A. Bindschadler, eds. The West Antarctic ice sheet: behavior and environment. Washington, DC, American Geophysical Union, 123-136.

Bingham, R.G., M.J. Siegert, D.A. Young and D.D. Blankenship. 2007. Organized flow from the South Pole to the Filchner-Ronne ice shelf: an assessment of balance velocities in interior East Antarctica using radio echo sounding data. J. Geophys. Res., 112(F3), F03S26. (10.1029/2006JF000556.)

Corr, H.F.J. and D.G. Vaughan. 2008. A recent volcanic eruption beneath the West Antarctic ice sheet. Nature Geosci., 1(2), 122-125.

Corr, H. and 8 others. 2007. Airborne radio-echo sounding of the Wilkes Subglacial Basin, the Transantarctic Mountains, and the Dome C region. Terra Antart. Rep., 13, 55-64.

Fujita, S. and 6 others. 1999. Nature of radio-echo layering in the Antarctic ice sheet detected by a two-frequency experiment. J. Geophys. Res., 104(B6), 13,013-13,024.

Harrison, C.H., 1971. Radio-echo sounding: focusing effects in wavy strata. Geophys. J. R. Astron. Soc., 24(4), 383-400.

Hodgkins, R., M.J. Siegert and J.A. Dowdeswell. 2000. Geophysical investigations of ice-sheet internal layering and deformation in the Dome C region of central East Antarctica. J. Glaciol., 46(152), 161-166.

Holt, J.W. and 8 others. 2006. New boundary conditions for the West Antarctic ice sheet: Subglacial topography beneath Thwaites and Smith glaciers. Geophys. Res. Lett., 33(9), L09502. (10.1029/2005GL025561.)

Jacobel, R.W., A.M. Gades, D.L. Gottschling, S.M. Hodge and D.L. Wright, 1993. Interpretation of radar-detected internal layer folding in West Antarctic ice streams. J. Glaciol., 39(133), 528-537.

Jacobel, R.W., T.A. Scambos, C.R. Raymond and A.M. Gades. 1996. Changes in the configuration of ice stream flow from the West Antarctic Ice Sheet. CRREL Spec. Rep. 96-27.

Joughin, I., E. Rignot, C.E. Rosanova, B.K. Lucchitta and J. Bohlander. 2003. Timing of recent accelerations of Pine Island Glacier, Antarctica. Geophys. Res. Lett., 30(13), 1706. (10.1029/2003GL017609.)

Leysinger Vieli, G.J.M., R.C.A. Hindmarsh and M.J. Siegert. 2007. Three-dimensional flow influences on radar layer stratigraphy. Ann. Glaciol., 46, 22-28.

Rignot, E.J. 1998. Fast recession of a West Antarctic glacier. Science, 281(5376), 549-551.

Rignot, E. 2002. Ice-shelf changes in Pine Island Bay, Antarctica, 1947-2000. J. Glaciol., 48(161), 247-256.

Rignot, E. 2006. Changes in ice dynamics and mass balance of the Antarctic ice sheet. Philos. Trans. R. Soc. London, 364(1844), 1637-1655.

Rignot, E. and 6 others. 2008. Recent Antarctic ice mass loss from radar interferometry and regional climate modelling. Nature Geosci., 1(2), 106-110.

Rippin, D.M., M.J. Siegert and J.L. Bamber. 2003. The englacial stratigraphy of Wilkes Land, East Antarctica, as revealed by internal radio-echo sounding layering, and its relationship with balance velocities. Ann. Glaciol., 36, 189-196.

Rippin, D.M., M.J. Siegert, J.L. Bamber, D.G. Vaughan and H.F.J. Corr. 2006. Switch-off of a major enhanced ice flow unit in East Antarctica. Geophys. Res. Lett., 33(15), L15501. (10.1029/2006GL026648.) 
Robin, G.de Q. and D.H.M. Millar. 1982. Flow of ice sheets in the vicinity of subglacial peaks. Ann. Glaciol., 3, 290-294.

Siegert, M.J. 1999. On the origin, nature and uses of Antarctic icesheet radio-echo layering. Progr. Phys. Geogr., 23(2), 159-179.

Siegert, M.J. and S. Fujita. 2001. Internal ice-sheet radar layer profiles and their relation to reflection mechanisms between Dome $C$ and the Transantarctic Mountains. J. Glaciol., 47(157), 205-212.

Siegert, M.J., A.J. Payne and I. Joughin. 2003. Spatial stability of Ice Stream D and its tributaries, West Antarctica, revealed by radioecho sounding and interferometry. Ann. Glaciol., 37, 377-382.

Stenoien, M.D. and C.R. Bentley. 2000. Pine Island Glacier, Antarctica: a study of the catchment using interferometric synthetic aperture radar measurements and radar altimetry. J. Geophys. Res., 105(B9), 21,761-21,779.

Vaughan, D.G. and 9 others. 2006. New boundary conditions for the West Antarctic ice sheet: subglacial topography beneath Pine Island Glacier. Geophys. Res. Lett., 33(9), L09501. (10.1029/2005GL025588.)

Whillans, I.M., J. Bolzan and S. Shabtaie. 1987. Velocity of Ice Streams B and C, Antarctica. J. Geophys. Res., 92(B9), 8895-8902.

Wingham, D.J., A. Shepherd, A. Muir and G.J. Marshall, 2006. Mass balance of the Antarctic ice sheet. Philos. Trans. R. Soc. London, 364(1844), 1627-1635. 